\title{
O consumo de produtos de moda baseado na vertente da sustentabilidade ambiental
}

\author{
The consumption of fashion products is based on environmental sustainability \\ Mirian Cristina de Lima \\ Mestre em Administração de Empresas pela Universidade de Fortaleza (UNIFOR). Professora da Universidade de \\ Fortaleza (UNIFOR) - mirian@unifor.br \\ Samantha Raquel Araújo Vaz \\ Especialista em Gestão e Negócios em Moda pela Universidade de Fortaleza (UNIFOR) - \\ samantharaquel@hotmail.com \\ Tábata Firmo de Carvalho Barbosa \\ Especialista em Gestão e Negócios em Moda pela Universidade de Fortaleza (UNIFOR) - tabatafcb@hotmail.com \\ Vanessa Figueiredo de Oliveira \\ Especialista em Gestão e Negócios em Moda pela Universidade de Fortaleza (UNIFOR) - vanessafiroli@hotmail.com
}

\section{Resumo}

Este artigo busca refletir sobre a temática da sustentabilidade ambiental e os fatores que incidiram para que a indústria da moda fosse apontada como uma das responsáveis pelos problemas ecológicos e sociais de hoje. Nesse cenário, várias marcas começaram a adotar uma linha de produção mais consciente por meio do eco marketing e da utilização do selo ISO 14001, desenvolver a gestão ambiental em suas empresas e industriais. O pensamento de muitos consumidores começou a voltar-se para as preocupações ambientais, originando o consumo consciente de moda. O surgimento do slow fashion e do design thinking como recursos utilizados para facilitar a ideia de consciência sustentável reforçaram novas ações, surge então um novo perfil de consumidores conscientes, eles têm uma preocupação com mundo de hoje e com os impactos para às gerações futuras e um pensamento ético. Essa é a nova vertente dos consumidores de moda.

Palavras-chave: Moda. Sustentabilidade ambiental. Consumo consciente. Marketing sustentável.

\begin{abstract}
This article seeks to reflect the environmental sustainability and the factors that led fashion industry to be identified as one of the responsible for today's ecological and social problems. In this scenario, several brands began to adopt a more conscious production line through eco-marketing and use of ISO 14001 seal, to develop environmental management in their companies and industrialists. The thinking of many consumers has begun to turn to environmental concerns, leading to conscious consumption of fashion. The emergence of slow fashion and design thinking as resources used to facilitate the idea of sustainable awareness reinforced new actions, a new profile emerges of conscious consumers, they have a concern with today's world and it's impacts for future generations and an ethical thinking. This is a new strand among fashion consumers.
\end{abstract}

Keywords: Fashion. Environmental sustainability. Conscious consumption. Sustainable marketing.

Recebido em: 24/07/2017

Aceito em: 26/03/2018 


\section{INTRODUÇÃO}

A Revolução Industrial, entre o final do século XVIII e o início do século XIX, acelerou o ritmo de produção devido à mecanização das indústrias que auxiliaram na redução dos preços das mercadorias, dando substrato material para o fortalecimento do sistema de moda, alavancando a produção dos vestuários e promovendo o consumo.

A Segunda Guerra Mundial transformou a indústria da moda, por conta da escassez da matéria-prima, o governo limitou o uso de determinados tipos de tecido e impôs seu racionamento. Toda essa situação fez com que as mulheres reformassem suas roupas, utilizando materiais alternativos na época, adotando um corte reto e masculino, seguindo um estilo mais simples. Até sua maquiagem era improvisada com elementos caseiros devido à carência de produtos (CARDOSO, 2011).

Durante esse período, surgiu o prét-a-porter (pronto para usar) que consistia na produção de roupas de qualidade em grande escala, onde os pedidos dos últimos modelos podiam ser feitos através de catálogos de venda por correspondência e eram confeccionados em até 24 horas pelos fabricantes. Apesar de todas as regras de racionamento, a moda sobreviveu à guerra (CARDOSO, 2011).

Após a Segunda Guerra mundial, a vida das pessoas foi voltando ao normal e as mulheres, que tiveram suas vaidades e desejos suprimidos durante todo o período de guerra, finalmente têm à sua disposição os recursos necessários para voltarem a cuidar de si. Aos poucos as indústrias de vestuário e cosméticos começaram a funcionar e recuperaram suas linhas de produção com um grande crescimento. Conforme os países iam se reestruturando, as possibilidades econômicas e o consumo das pessoas aumentavam cada vez mais (SANA, 2013).

Como uma forma de celebrar o fim de uma época sombria de guerra, tendeu-se a exagerar um pouco, até mesmo como uma forma de compensação. Após um longo período de roupas simples e sem nenhum glamour, em 1947 o estilista francês Christian Dior criou o "New Look" para as mulheres, em uma coleção que trouxe de volta a elegância, sofisticação e a feminilidade que não se via há algum tempo. O New Look estimulou o retorno da indústria têxtil, por conta da quantidade de tecidos usadas na sua confecção, bem como impulsionou o crescimento da produção de todos os fabricantes de acessórios que acompanhavam essas roupas (SANA, 2013). 
Os empreendedores da época não se preocupavam com os impactos ambientais e sociais resultantes de todo o processo de industrialização, assim, agravando a poluição do ar, da terra, das águas e o grande gasto de recursos naturais.

Por conta desse aumento da produção e do consumo, surgiram crises ambientais que começaram a preocupar especialistas, ambientalistas e estudiosos do assunto, levando a uma reflexão que atingiu proporções internacionais e de cunho político, gerando ações como: a Conferência de Estocolmo em 1972 e a Eco-92 ou Rio-92 em 1992.

O marketing sustentável surgiu em decorrência dessa preocupação com o planeta, instigando a uma moda com uma vida cíclica maior, uma produção mais limpa, condições laborais justas etc.

A sustentabilidade está se enraizando na moda devido as mudanças no comportamento e nos hábitos dos consumidores e por esse motivo efetivamente percebemos profundas mudanças nos últimos anos, pois o consumidor se encontra cada vez mais atento às questões sociais e ecológicas, adquirindo produtos de empresas que tenham a mesma preocupação e os cuidados com o meio ambiente.

Esse artigo discute assuntos dentro do contexto da moda com a sustentabilidade ambiental como: critérios de sustentabilidade na moda, o uso da certificação ISO 14001, slow fashion, fast fashion, design thinking, marketing sustentável, consumo consciente.

\section{MODA SUSTENTÁVEL}

\section{Conceito de sustentabilidade}

O conceito de sustentabilidade começou a ser desenvolvido em 1972 na Conferência das Nações Unidas sobre o Meio Ambiente Humano, também conhecida como Conferência de Estocolmo, foi a primeira grande reunião internacional organizada pela Organização das Nações Unidas (ONU) para tratar sobre questões relacionadas as atividades humanas em relação ao meio ambiente (REPORT..., 1987).

No entanto, somente em 1987 no Relatório de Brundtland foi criada a primeira definição de desenvolvimento sustentável, que consiste no desenvolvimento que satisfaz as necessidades do presente sem comprometer a possibilidade de gerações futuras satisfazerem suas próprias necessidades (REPORT..., 1987). 
Contudo, no início dos anos 90, observou-se o crescimento desenfreado do consumo, gerando o aumento ainda maior da degradação ambiental, poluição, escassez de recursos naturais, entre outros problemas sociais e ecológicos.

Foi então que em 1992 houve a Conferência das Nações Unidas sobre o Meio Ambiente e o Desenvolvimento, também conhecida como Eco-92 ou Rio-92, realizada no Rio de Janeiro, cujo objetivo era tratar sobre os problemas ambientais mundiais, introduzindo a ideia do desenvolvimento sustentável, de um modelo de desenvolvimento econômico menos consumista e mais apropriado ao equilíbrio ambiental. A diferença da Conferência de Estocolmo para a Eco-92 é que nesta houve a presença maciça de vários chefes de Estado, confirmando ainda mais a importância da questão ambiental no início dos anos 1990 (OLIVEIRA, 2012).

Durante a Eco-92, observou-se que o debate acerca do desenvolvimento sustentável evoluiu para a esfera de três pilares da sustentabilidade, que consistem na proteção ambiental, no desenvolvimento econômico e no desenvolvimento social. Para alcançar a sustentabilidade não basta apenas observar os aspectos de cunho ambiental, uma vez que estes não são o suficiente para solucionar os problemas de uma economia global sustentável. É necessário que esses três pilares interajam entre si, pois firmam a ideia de se construir uma sociedade autossuficiente sem agredir o meio ambiente.

A partir dos pilares do Desenvolvimento Sustentável - o ambiental, o social e o econômico e das discussões de ordem mundial sobre novos paradigmas de consumo e comportamento ressalta-se as mudanças culturais que precisam ocorrer a curto, médio e longo prazo para que se alcance a qualidade de vida almejada pela maioria da população do planeta que vive abaixo da linha da miséria (CAVALCANTE et al. 2012).

\section{Pilares da sustentabilidade}

A "Proteção Ambiental" como pilar da sustentabilidade tem por objeto: "[...] analisar a interação de processos com o meio ambiente sem lhe causar danos permanentes" (OLIVEIRA; MARTINS; LIMA, 2010, p. 4). Em outras palavras, minimizar todos os impactos ambientais ocasionados pela produção industrial. Incide em toda e qualquer conduta que possui direta ou indiretamente impactos ambientais de curto, médio ou longo prazo. 
O "Desenvolvimento Social" abrange o capital humano que se relaciona direta ou indiretamente com as atividades desenvolvidas por uma empresa. Oliveira, Martins e Lima (2010) ressaltam a importância do estabelecimento de ações justas para trabalhadores, parceiros e sociedade.

O "Desenvolvimento Econômico" vai além do seu significado superficial relacionado à questão monetária. O principal ponto nesse contexto: “[...] é a criação de empreendimentos viáveis e atraentes para os investidores" (OLIVEIRA MARTINS; LIMA, 2010, p. 4). As empresas não devem trabalhar gerando um desequilíbrio no meio ambiente. Podemos citar exemplos como: a exploração dos trabalhadores e as péssimas condições laborais dos funcionários, degradação do meio ambiente etc.

\section{Sustentabilidade e moda}

Nos últimos anos, o tema sustentabilidade é cada vez mais discutido em virtude da crise ambiental e do consumismo exagerado. Dessa forma, o desenvolvimento sustentável começa a ser pensado e aplicado na moda ao buscar uma maneira de solucionar os problemas gerados por essa indústria ao considerar as questões sociais e ecológicas.

Por mais que a moda possa objetivar o consumo e a produção, muitas vezes com um ciclo de vida limitado em que a satisfação do consumo do produto tem caráter tanto físico como emocional, tem-se buscado um novo paradigma no qual se procura trabalhar com a produção de peças ambientalmente corretas, seja na escolha dos materiais têxteis ou na redução, reutilização e reciclagem de materiais que não degradem o meio ambiente (ARAÚJO, 2014).

Pode-se definir a moda sustentável como sendo o processo de produção das peças de vestuário que incorporam os princípios de um comércio justo, com condições livres de trabalho, sem prejudicar seus funcionários ou o meio ambiente. O processo faz uso de materiais biodegradáveis e orgânicos, com design projetado para uma vida mais longa do produto, tudo conforme o sistema ético de produção (KABUKCU; ENSARI, 2016).

A moda sustentável também é conhecida como moda verde ou eco fashion, como é reconhecida internacionalmente, ela procura utilizar tecidos reciclados ou produzidos organicamente, diminuindo o consumo de energia elétrica e água, utilizando os resíduos 
decorrentes da produção da melhor forma possível de uma maneira que o respeito ao meio ambiente sempre venha em primeiro lugar.

As decisões tomadas durante o processo de criação e fabricação de um produto afetam em até $80 \%$ os impactos sociais e ambientais desse produto no ecossistema. Ou seja, as escolhas feitas dos materiais, sua forma, montagem, cor e sistema de produção afetam todo o ciclo de vida do objeto e o designer desses produtos acaba influenciando os padrões de consumo sustentável (KABUKCU; ENSARI, 2016).

O design sustentável estimula um planejamento racional dos recursos implícitos no ciclo de vida do produto. E o designer consciente tem a função de espalhar responsabilidade e senso comum nos produtos que ele projetou, para minimizar os impactos prejudiciais ao meio ambiente (MORAIS; CARVALHO; BROEGA, 2011).

Pode-se inferir que para que as empresas de moda sejam consideradas sustentáveis "[...] todas as fases de criação de um serviço ou produto, devem ser acompanhadas por metodologias sustentáveis e integradas, desde a distribuição do produto, passando pelo uso, até o seu descarte" (MORAIS; CARVALHO; BROEGA, 2011, p. 389, tradução nossa).

O grande desafio para a moda no âmbito da sustentabilidade "[...] consiste na preocupação com a preservação do meio ambiente por meio do processo produtivo e do ciclo de vida dos produtos" (REFOSCO et al. 2011, p. 5).

\section{Critérios de sustentabilidade na moda}

Conforme o site Eco Fashion World, existem oito critérios a serem abordados dentro do conceito de uma moda sustentável: vegano, produção ética, produção artesanal, customização de peças, comércio justo certificado, orgânico, reciclado e vintage (ECO FASHION WORLD, 2017).

Veganos são aqueles produtos fabricados sem o uso de couro ou tecidos de origem animal; produção ética é aquela que respeita as pessoas e o meio ambiente; produção artesanal consiste nos produtos criados através da habilidade dos artesãos que preservam as tradições dos seus ancestrais; customização de peças é transformar produtos que iam ser descartados em novos materiais ou peças, valoriza o upcycling e o slow fashion; comércio justo certificado determina normas referentes ao trabalho internacional, tais como horas de trabalho razoáveis, direito de sindicalizar-se, salário digno e acabar com o trabalho infantil; orgânico diz respeito às fibras 
naturais cultivadas sem o uso de pesticidas e outros materiais tóxicos; reciclado é tudo aquilo feito a partir de materiais já existentes, sejam fibras, tecidos ou metais; e vintage que são peças antigas e de excelente qualidade ainda em uso criadas entre 1920 e 1975 (ECO FASHION WORLD, 2017).

\title{
Selo ISSO 14001
}

A norma ISO 14000 da International Standards Organization é um selo padrão, foi criado durante a Rio-92 e trata sobre a gestão do meio ambiente e designa o que as corporações devem fazer para tornar mínimos os impactos ambientais das suas ações e melhorar constantemente suas atuações na esfera ambiental (RIEKSTI, 2012).

Depois surgiu a norma ISO 14001, que tem sido o instrumento mais utilizado para desenvolver a gestão ambiental em empresas industriais e a única norma "certificável" da família ISO 14000 (RIEKSTI, 2012). Segundo a Associação Brasileira de Normas Técnicas (ABNT, 2015, p. 16) a ISO 14001:

\begin{abstract}
Especifica os requisitos para um sistema de gestão ambiental que uma organização pode usar para aumentar seu desempenho ambiental. Esta Norma é destinada ao uso por uma organização que busca gerenciar suas responsabilidades ambientais de uma forma sistemática, que contribua para o pilar ambiental da sustentabilidade. Auxilia uma organização a alcançar os resultados pretendidos de seu sistema de gestão ambiental, os quais agreguem valor para o meio ambiente, a organização em si e suas partes interessadas. Os resultados pretendidos de um sistema de gestão ambiental coerente com a política ambiental da organização incluem: - aumento do desempenho ambiental; atendimento dos requisitos legais e outros requisitos; - alcance dos objetivos ambientais. É aplicável a qualquer organização, independentemente do seu tamanho, tipo e natureza, e aplica-se aos aspectos ambientais das suas atividades, produtos e serviços que a organização determina poder controlar ou influenciar, considerando uma perspectiva de ciclo de vida.
\end{abstract}

Para Rieksti (2012) há seis passos que as empresas devem seguir para a obtenção do certificado ISO:

- Desenvolver política ambiental;

- Identificar atividades com interação com o meio ambiente;

- Verificar requisitos legais e regulatórios;

- Demonstrar prioridades da empresa e seus objetivos para redução de impacto ambiental; 
- Ajustar a estrutura organizacional para tais objetivos, realizando treinamentos, devidamente comunicados e documentados;

- Checar, para eventual correção, o sistema de gestão ambiental.

\section{A ABORDAGEM ETNOGRÁFICA COMO MÉTODO CIENTÍFICO}

\section{Marketing sustentável}

As marcas são ícones da sociedade de consumo, os consumidores querem se sentir representados pelos valores exibidos nas propagandas e muitos buscam uma diferenciação para se representarem socialmente através do capital econômico. O excesso de ofertas, o grande número de peças na linha de produção das empresas e toda a comunicação exacerbada contribuem de alguma forma para o consumo compulsivo.

O marketing está inserido dentro de um universo de possibilidades de comunicação com o mercado, favorece o consumismo acelerado e pode abandonar a qualidade de vida. A sociedade passou a ter uma grande preocupação com o corpo social atual e das gerações futuras de maneira ética e responsável, surgindo assim o marketing sustentável, ou marketing verde, a fim de direcionar as pessoas para essa nova visão de mundo. Segundo Lovato (2013), esta visão que o ser humano tem em relação ao meio ambiente não condiz com o meio ecológico no qual vivenciamos hoje. Todos os prejuízos ambientais ocasionados desse consumismo em massa refletem diretamente na sociedade.

Diversas empresas surgiram em um período em que a maior preocupação era o lucro, não havia responsabilidade social e nem um pensamento nas consequências dos impactos causados ao meio ambiente, as empresas precisaram reavaliar a importância desse novo contexto na sua atuação, ao produzir com um cuidado maior com os descartes e respeitando o ciclo de renovação da natureza. Hoje, algumas dessas organizações realmente olham a sustentabilidade ambiental com uma maior importância, ocasionando mudanças na produção de uma forma consciente. Porém, ainda existe uma parte das empresas em que o pensamento e a preocupação ambiental é apenas simbólico (LOVATO, 2013). Quando uma empresa aceita os novos conceitos de sustentabilidade ela se preocupa em colocar produtos no mercado e divulgar suas ações por meio do marketing sustentável, o que gera nos dias de hoje a confiança do consumidor cada vez mais exigente e preocupado com o pré-consumo. 
Em função das exigências da sociedade, no sentido de minimizar a diferença verificada entre os resultados econômicos e sociais, bem como da preocupação ecológica, em face de sua relevância para a qualidade de vida das populações, têm-se exigido das empresas um novo posicionamento em sua interação com o meio ambiente (ANDRADE, TACHIZAWA, CARVALHO, 2003).

As pessoas que querem consumir produtos sustentáveis desejam que essas empresas permaneçam no mercado seguindo os princípios da sustentabilidade. Quando a mesma não consegue manter esses padrões, rapidamente há o rompimento dessa relação, pois há clientes que pagam mais por um produto que passa por um processo de produção sustentável.

Cada vez mais surgem corporações que querem transformar o seu produto a fim de gerar um consumo consciente, no qual ética e estética não podem se separar. Uma marca que já nasce sustentável encontra-se a frente das outras que precisam se reposicionar como sustentável, pois ela tem que se adaptar a esse padrão fazendo um replanejamento em seu grupo.

\section{Fast fashion versus slow fashion}

A indústria da moda prejudica muito o meio ambiente por meio do gasto de energia, embalagens descartadas que vão acabar no lixo, o uso em excesso da água, contaminação dos rios, a mão de obra escrava, o trabalho infantil, dentre outros. Entender o funcionamento da produção das peças de vestuário é um fator primordial no mundo em que vivemos hoje e ter consciência antes de produzir é muito importante para as empresas saberem o que fazer com o que sobra daquilo que elas produzem.

O fast fashion é um fenômeno efêmero, uma moda rápida principalmente nas vitrines. Possui uma produção em massa de variedades, porém com estoque pequeno, onde a loja oferece novidades semanalmente. Gera no cliente a sensação de que ele precisa consumir a roupa imediatamente antes que a mesma acabe (CIETTA, 2010).

Os produtos são consumidos e descartados em alta velocidade, em um processo de baixo custo e com uma baixa qualidade, obtido geralmente por meio de uma mão de obra com condições duvidosas. Essa indústria do fast fashion viciou o consumidor numa moda descartável e rápida com o desejo de ter um guarda-roupa enorme, com muitos itens adquiridos da compra por impulso em um curto período de tempo e sem montar um visual coerente. As pessoas que consomem moda 
dessa forma esquecem que, além de ser uma indumentária, a moda expressa a sua personalidade e um estilo, foi assim ao longo da história. Maria Antonieta, que usava roupas extravagantes, perucas volumosas e chapéus chamativos é um exemplo de uma comunicação não verbal conectada à personalidade que envolve as crenças, religiões, costumes, culturas, fatores genéticos e fisiológicos.

O sistema de moda dos desfiles, coleções de primavera, verão, outono e inverno no qual tudo era criado da noite para o dia, com foco na indústria da moda tem como oposto o slow fashion, onde a moda segue um pouco mais devagar em peças de design atemporais resistindo por mais tempo incorporando o conceito de sustentabilidade econômica e ambiental (CABRAL, 2013). Portanto, o consumidor tem como saber quem e como foi produzido e ainda assim de onde vem a matéria prima. As peças do slow fashion são bem mais trabalhadas, de alta qualidade, visto que o impacto ambiental é menor, as marcas geralmente são locais e artesanais. Também não produzem estoque, porque geralmente o material a ser usado é feito e comprado sob medida, reduzindo o lixo no meio ambiente.

Essa abordagem lenta intervém como um processo revolucionário no mundo contemporâneo, que incentiva levar mais tempo para garantir mais qualidade, criatividade, ética, e para dar valor ao produto e contemplar a conexão com o meio ambiente (CARVALHAL, 2016).

Diante de um tema tão discutido, muitas marcas começaram a rever suas ações e adequar seus processos para diminuir os impactos ao meio ambiente, como realizar o reaproveitamento dos materiais usados e o que seria descartado dentro da produção é transformado em produto. Podese citar algumas grandes empresas que adotaram esse método: a Prada desenvolveu uma coleção de bolsas e sapatos com estoque antigo de estampas; a Levi's criou uma coleção de jeans feitos a partir de restos de redes de pesca e carpete e a Louboutin criou o sapato Eco Trash, que foi produzido de materiais recicláveis e biodegradáveis (juta, PVC, cortiça). Tudo isso prova que a moda é uma grande plataforma de transformação de descarte de matéria prima que podem resultar em soluções criativas e econômicas.

Uma vertente do slow fashion é o engajamento dos estilistas na confecção de roupas e acessórios a partir de uma ideia de consciência sustentável. O estilista Ronaldo Fraga costuma defender esse tipo de prática em suas temáticas de coleção com o uso de fibras naturais orgânicas e reaproveitamento de retalhos de confecção (TEIXEIRA; POMPERMAYER, 2013). Carlos Bacchi já chegou a fazer uma coleção em que a matéria prima era natural, forma artesanal em tear 
totalmente manual, sem o uso de energia elétrica, adotou tingimentos orgânicos como eucalipto, pêssego e cana. Tudo isso resultou em vestidos que podem ser usados hoje e daqui há muitos anos.

O pós-consumo faz parte do questionamento das empresas, pois o impacto ambiental também se torna uma preocupação ao longo do descarte do consumidor. Por exemplo, é difícil saber o destino final que uma peça de vestuário terá, se será reciclada, doada, reaproveitada etc.

\section{Design thinking: um novo design}

Design Thinking é um recurso referente a maneira de pensar do designer, cuja finalidade é suprir as necessidades humanas tomando base de questionamentos. A começar com perguntas formuladas e serem respondidas no decorrer das observações do problema apresentado, com o intuito de auxiliar as organizações a juntarem a inovação com a criatividade. Portanto, a solução não se origina do problema, deve se adaptar a ele (VIANNA et al., 2012).

O papel do designer, dentro do contexto do design thinking é buscar resolver problemas do dia a dia dos usuários, observar o mundo e criar alternativas que atendam às necessidades dos clientes de uma forma mais humana. E assim, desenvolver produtos o mais funcionais possíveis.

Para que esse processo tenha sentido, é necessário valorizar a empatia, obter colaboração para projetar e experimentar soluções que fazem parte da vida das pessoas. É um instrumento importante para as empresas, pois esse novo produto contribui para o desenvolvimento de soluções de problemas em relação ao grande desafio que é a sustentabilidade ambiental. É levado em consideração o olhar do ser humano, do negócio e a respeito da tecnologia.

Quando duas ou mais pessoas se reúnem, elas podem simplesmente trocar informações de maneira rotineira, ou podem realmente se comunicar entre si, ou ainda, podem se engajar em uma conversação (dar e receber) altamente absorvente e sinérgica que resolva uma necessidade comum, ou em outras palavras, em uma colaboração intensa (MILLS, 1998).

É uma abordagem recorrente e colaborativa, pois se acredita que várias mentes juntas agregam um maior pensamento inovador, é também experimental, o designer possui a liberdade de errar e aprender com os mesmos, estimulando obter uma visão rápida de ideias para os projetos. Esse método ajuda as empresas a entenderem melhor as pessoas, criando produtos que sejam mais relevantes. As organizações que adotaram essa nova perspectiva criam setores novos e trocam as regras de engajamento com o cliente, para que ele possa dar sugestões e orientar a 
empresa na solução de um determinado produto ou serviço obtendo uma liderança sustentável e atendendo as necessidades básicas humanas. A moda deve se engajar a esse conceito, na perspectiva de agradar o novo perfil de consumidores.

\section{O CONSUMO CONSCIENTE}

Com o sistema capitalista que vivemos, em que tempo é dinheiro, o consumo se torna acelerado e consequentemente há o aumento exacerbado da produção. Porém, sabe-se que os recursos naturais são escassos, que há o aumento da desigualdade social, pois os recursos não são para todos e que produzimos mais lixo do que o planeta pode suportar. Com isso, as pessoas se perguntam: aonde esse consumo exagerado vai chegar? Elas estão cada vez mais atentas e preocupadas com o rumo do planeta.

A partir desse pensamento, os consumidores da moda estão valorizando o desaceleramento do consumo, lifestyle slow.

\section{Uma nova era de consumidores conscientes}

Muitos estão enaltecendo o "ser" e não o "ter", uma mudança cultural, social e estrutural. Para o visionário de Dee Hock, fundador e diretor executivo da Visa Internacional, as pessoas perceberiam um novo sentido para a vida.

Estamos em um momento de mudança cultural, científica, social e institucional muito maior do que qualquer outra que o mundo já tenha passado. Temos à frente a possibilidade de regeneração da individualidade, da liberdade, da comunidade e da ética como o mundo nunca conheceu, e de uma harmonia com a natureza, com os outros e com a inteligência divina como o mundo jamais sonhou (HOCK, 2000).

Podemos antever que futuramente a sociedade industrial e capitalista seja substituída por uma sociedade do conhecimento e da consciência. Não podemos negar que as tentações são muitas, como não comprar aquela blusa do seu estilista favorito que fez parceria com uma fast fashion. É só pensarmos que essa empresa alimenta um mercado colonizador, que explora condições de trabalhos sub-humanas em países paupérrimos, do qual não possuem ou tem pouquíssimas leis trabalhistas e que essa compra não estimulará a produção local. 
No Brasil, segundo a Global GFK, $71 \%$ das pessoas só consomem produtos e serviços que tenham a ver com seus valores, ideais e crenças (GFK, 2015).

A nova era de consumidores não quer apenas uma beleza a olhos vistos, ela quer muito mais do que isso, ela quer o consumo de um produto que torne o mundo mais justo, mais saudável e mais agradável de viver.

\section{A identidade e a consciência}

As pessoas estão entendendo a moda como uma extensão do nosso corpo, pois ela não apenas nos cobre, mas também nos dá identidade, mostram nosso humor, nossas vontades e o que queremos para nossa vida. Podemos expor isso de diversas formas, com camisetas que possuem frases ou símbolos, nas cores, no tipo de tecido, de corte, etc. O designer e empreendedor, Alan Bruno, do site Update or Die, em seu post "Por que minha lojinha de brownies não vai dar certo?", comenta:

\footnotetext{
Hoje as marcas são como as pessoas com que escolhemos conviver/estar. Elas fazem parte do nosso cotidiano, conversam com a gente, muitas vezes nos dão "conselhos motivacionais" e têm personalidade própria. Escolhemos nossos amigos, namorados ou qualquer outro relacionamento afetivo por questões de empatia, de identificação, de reconhecimento de ideais (BRUNO, 2015, p. 2).
}

Podemos escolher o que queremos mostrar e como queremos ser vistos. Talvez, por isso, cada vez mais a moda esteja com menos regras para se vestir, sem precisar necessariamente usar o último lançamento ou a tendência do momento.

\section{Uma vida compartilhada: o consumidor com o pensamento coletivo}

As gerações mais novas querem ter mais acesso do que posse, elas são adeptas da economia do compartilhamento. Ter um carro ou uma casa própria para elas é coisa antiga, normalmente elas preferem morar de aluguel perto de seu trabalho sem se sentir presa, pois se acaso mudar de trabalho vai poder mudar de moradia também, em vez de ter o último lançamento de carro, a ideia é andar de transporte público ou se o trabalho for perto ir de bicicleta ou a pé, em vez de trabalhar em uma grande sala só para ela, compartilhar uma sala com várias pessoas de diversas profissões para trocar experiências, o conhecido coworking, em vez de comprar uma roupa 
em uma fast fashion, comprar em um bazar ou em um brechó por um preço bem menor e uma peça singular.

São jovens que enxergam a humanidade como uma única família e o planeta como uma comunidade que se compartilha. Para eles o propósito da vida está além de consumir e ter um produto, está em adquirir experiências e vivenciá-las.

Vemos muitas guerras, um mundo intolerante e, em contrapartida, existe uma parte do mundo mais informada e mais consciente das causas sociais e culturais. Exigindo que as marcas tenham uma postura sem preconceitos, que respeitem o meio ambiente e a sustentabilidade.

Não basta olhar a vitrine ou um lookbook, as pessoas querem uma relação amiga, um batepapo, um lugar que possa tirar todas as suas dúvidas e saber: Quem fez sua roupa? Que materiais utilizou? De onde eles vieram? Como as peças foram feitas? Essas foram algumas das perguntas disseminadas nas redes sociais no dia 24 de abril de 2014, titulado como Fashion Revolution Day, após um ano da queda de um edifício que produzia vestuário para cerca de 28 marcas, como Benetton, Mango e Primark, deixando mais de mil trabalhadores mortos e outros 2,5 mil feridos (CARVALHAL, 2016).

Em 2015, a ação ganhou força no Brasil, foram mais de setenta países celebrando a consciência do consumidor e o verdadeiro custo de nossas roupas, que podem custar vidas. Consumir uma moda consciente evita a poluição ambiental, o trabalho escravo, o trabalho infantil e consequentemente, diminui tragédias.

A blogueira Carla Lemos, da Modices, já percebe mudanças em suas leitoras:

Acho que o grande lance agora é que as pessoas estão tendo mais consciência de si e do seu papel no mundo. Foi um movimento que alguns blogs ajudaram a promover, porque antes as revistas não falavam disso. É muito bom de ver, a cada novo caso de escravidão ou de coisas negativas que acontecem na indústria, ou até mesmo coisas positivas relacionadas a consumo consciente, mais e mais pessoas compartilhando. Não é só mais o look do dia ou a nova bolsa que elas querem compartilhar (LEMOS, 2015? apud CARVALHAL, 2016, p. 186)

Com a internet e as redes sociais presentes na vida das pessoas, as notícias estão circulando com mais rapidez. Todos os dias recebemos vários e-mails e olhamos nas redes sociais muitas 
imagens de produtos ou estilo de vida, as pessoas estão tendo o hábito de compartilhar fotos que gostam ou se identificam, surgindo assim os digital influencers.

A influência de personalidades como, Anne Hathaway, Emma Watson, Yasmin Brunet, etc. que adotaram os costumes de moda sustentável tanto no seu dia a dia como no red carpet, são modelos que ajudam a fortalecer e expandir o conhecimento e costumes de consumir conscientemente.

Dado o exposto, pode-se inferir que, ao vestir uma peça de roupa presumidamente ecológica, o usuário anteriormente considerado por dois dos autores supracitados como uma "vitrina ambulante", pode sensibilizar, conscientizar e inspirar outras pessoas a consumirem de maneira sustentável ou, simplesmente, despertar o desejo de compra de produtos "verdes" (ARAÚJO; LOPES, 2014).

O mundo virtual torna as pessoas mais vigilantes e o público exige mais explicações e transparência na relação empresa e consumidor. São imagens, textos, vídeos que influenciam o cotidiano das pessoas e que no consciente ou no subconsciente elas acabam levando para sua vida real novos hábitos e valores. Não sabemos se estamos a poucos passos de uma vida e um planeta mais saudável, mas temos a certeza que com esse mundo de possibilidades podemos nos conscientizar para realizarmos esse sonho.

\section{CONSIDERAÇÕES FINAIS}

No século XX, com o aperfeiçoamento das técnicas industriais, a produção e o consumo cresceram consideravelmente. Devido a isso, as pessoas começaram a se preocupar com as próximas gerações e o seu futuro após esse consumo desenfreado.

A sustentabilidade ambiental tornou-se pauta principal em eventos de importância mundial, instigando a surgir uma nova era de marcas no espaço da moda e uma nova era de consumidores, todos ligados a um pensamento, o de consumir para ser e não para ter, tornando-se possível a moda verde ou o eco fashion. O marketing que tinha como único objetivo vender para lucrar, passa a ter um objetivo maior, vender para se ter experiências prazerosas.

As redes sociais passaram a ser um meio de comunicação de grande importância para as marcas e para os consumidores, por ser uma ferramenta democrática, sustentável e de longo alcance, elas influenciam bastante o público que compartilham pensamentos e ideias similares a 
respeito desse novo lifestyle, levando cada vez mais pessoas e empresas a aderirem esses hábitos conscientes.

A tendência é que esse novo tipo de mercado de moda sustentável aumente, atingindo até mesmo as marcas de fast fashion, cujo intuito é a produção em massa para o consumo desenfreado. Se elas não entrarem nesse novo movimento perderão um grande percentual de clientes, uma vez que um grupo considerável de pessoas acreditam nesse estilo de vida "verde" e deixarão de consumi-las.

Em contraponto a um mundo com guerras, intolerância, individualidade e desigualdade, uma nova geração surge para revogar todos os pensamentos negativos e desesperançosos do rumo do planeta, compartilhando o seu espaço, tempo, vestimentas e tudo que for possível para se viver sustentável, saudável e realizada.

\section{REFERÊNCIAS}

ABNT. ASSOCIAÇÃO BRASILEIRA DE NORMAS TÉCNICAS. NBR ISO14001. Sistemas de gestão ambiental - requisitos com orientações para uso. Rio de Janeiro: ABNT, 2015.

ANDRADE, Rui Otávio Bernardes; TACHIZAWA, Takeshy; CARVALHO, Ana Barreiros de. Gestão ambiental: enfoque estratégico aplicado ao desenvolvimento sustentável. 2. ed. São Paulo: Pearson, 2003.

ARAÚJO, Gabriella Ribeiro da Silva; LOPES, Camila Santos Doubek. O novo luxo e o ecoconsumismo. IARA: Revista de Moda, Cultura e Arte, São Paulo, v.7, n. 2, p. 175-191, 2014.

ARAÚJO, Mariana Bezerra Moraes de. Marcas de moda sustentável: critérios de sustentabilidade e ferramentas de comunicação. 2014. 123 f. Dissertação (Mestrado em Design de Comunicação de Moda) - Escola de Engenharia, Universidade do Minho, Braga, 2014. Disponível em: <repositorium.sdum.uminho.pt/handle/1822/33978>. Acesso em: 3 abr. 2017.

BRUNO, Alan. Por que minha lojinha de brownies não vai dar certo? In: UPDATE OR DIE!. Base de dados. 2015. Disponível em: <http://www.updateordie.com/2015/09/28/por-que-minha-lojinhade-brownies-nao-vai-dar-certo>. Acesso em: 30 abr. 2017.

CABRAL, Henrique. Slow Fashion. In: CLICHE. Base de dados. 2013. Disponível em: http://www.revistacliche.com.br/2013/04/slow-fashion/. Acesso em: 4 abr. 2017.

CARDOSO, Cyn. Anos 40: a moda e a Segunda Guerra Mundial. In: DEMOCRACIA FASHION: arte, design, moda, música, mitologia. Base de dados. 2011. Disponível em: 
<http://democraciafashion.com.br/2011/03/23/anos-40-a-moda-e-a-segunda-guerra-mundial/>. Acesso em: 22 maio 2018.

CARVALHAL, André. Moda com propósito: manifesto pela grande virada. Rio de Janeiro: Paralela, 2016.

CAVALCANTE, Ana Luisa Boavista Lustosa; et al. Design para a sustentabilidade: um conceito interdisciplinar em construção. Projética: Revista Científica de Design, Londrina, v. 3, n. 1, p. 252263, jul. 2012. Disponível em:

<http://www.uel.br/revistas/uel/index.php/projetica/article/view/12384/11341>. Acesso em: 5 abr. 2017.

CIETTA, Enrico. A revolução do fast fashion: estratégias e modelos organizativos para competir nas indústrias híbridas Tradução de Glaucia Britto e Kathia Castilho. São Paulo: Estação das Letras e Cores, 2010.

ECO FASHION WORLD. Eco fashion world eco-criteria. Disponível em: <http://www.ecofashionworld.com/eco-criteria.html>. Acesso em: 5 abr. 2017.

GFK. Responsabilidade ambiental e compra ética. Banco de dados. 2015. Disponível em: <http://www.gfk.com/pt-br/insights/report/responsabilidade-ambiental-e-compra-etica/>. Acesso em: 30 mar. 2017.

HOCK, Dee. Nascimento da era caórdica. São Paulo: Cultrix, 2000.

KABUKCU, Evrim; ENSARI, Şebnem. Muhterem. Eco-concepts \& ethical issues in sustainable fashion industry: bemateks-kids fashion group. International Journal of Research In Social Sciences, Índia, v. 6, n. 5, p. 11- 22, mar. 2016. Disponível em: <http://www.ijsk.org/wpcontent/uploads/2015/12/2-FASHION-INDUSTRY.pdf>. Acesso em: 6 mar.2017

LOVATO, Marcos Luiz. Greenwashing no Brasil: quando a sustentabilidade ambiental se resume a um rótulo. Revista Eletrônica do Curso de Direito da UFSM, Santa Maria, v. 3, esp., p. 162 - 171, 2013. Disponível em:

<https://periodicos.ufsm.br/revistadireito/article/view/8257/4978\#.WPftBvnyvlU> Acesso em: 19 abr. 2017.

MILLS, Anthony. Collaborative engineering and the internet: linking product development partners via the web. Dearbon: SME, 1998.

MORAIS, Carla; CARVALHO, Cristina; BROEGA, Ana Cristina. A design tool to identify and measure the profile of sustainable conscious fashion costumer. In: AUTEX CONFERENCE, 8., 2011, Mulhouse. Anais... Mulhouse: AUTEX, 2011. p. 388-393. Disponível em: <http://repositorium.sdum.uminho.pt/bitstream/1822/14928/1/artigo\%20AUTEX_MORAIS_CARVA LHO_BROEGA.pdf>. Acesso em: 3 mar. 2017. 
OLIVEIRA, Leonardo Dias de. A conferência do Rio de Janeiro - 1992 (Eco-92): reflexões sobre a geopolítica do desenvolvimento sustentável. In: ENCONTRO NACIONAL DA ANPPAS, 6., 2012, Belém. Anais... Belém: ANPPAS, 2012. Disponível em: <http://www.anppas.org.br/encontro6/anais/ARQUIVOS/GT15-170-31-20120626115525.pdf>. Acesso em: 31 mar. 2017.

OLIVEIRA, Lucas Rebello de; MARTINS, Eduardo Ferraz; LIMA, Gilson Brito Alves. Evolução do conceito de sustentabilidade: um ensaio bibliométrico. Relatórios de Pesquisa em Engenharia da Produção, Rio de Janeiro, v. 10, n. 4. p. 1-17, 2010. Disponível em: <http://www.producao.uff.br/conteudo/rpep/volume102010/RelPesq_V10_2010_04.pdf>.Acesso em: 2 abr. 2017.

REFOSCO, Ereany; et al. O novo consumidor de moda e a sustentabilidade. 2011. In.: COLÓQUIO DE MODA, 7., 2011, Paraná. Anais... Paraná: REDEModa, 2011. p. 1- 10. Disponível em: <https://repositorium.sdum.uminho.pt/bitstream/1822/14946/1/Cbroega_04.pdf>. Acesso em: 04 abr. 2017.

RIEKSTI, Ana Carolina. ISO 14001 e a sustentabilidade: a eficácia do instrumento no alcance do desenvolvimento sustentável. In: MARCOVITCH, Jacques (Org.). Certificação e sustentabilidade ambiental: uma análise crítica. São Paulo: USP, 2012. 17-35. Disponível em: <http://www.usp.br/mudarfuturo/cms/wp-content/uploads/Certifica\%C3\%A7\%C3\%A3o-eSustentabilidade-Ambiental-Trabalho-Final_261012.pdf>. Acesso em: 4 mar. 2017.

REPORT of the World Commission on Environment and Development: our common future. 1987. Disponível em: <http://www.un-documents.net/our-common-future.pdf>. Acesso em: 30 mar. 2017.

SANA. 1940: militarismo, new look e Carmen Miranda. In: HISTÓRIA DA MODA. Base de dados. 2013. Disponível em: <http://modahistorica.blogspot.com.br/2013/05/1940-militarismo-new-looke-carmen_28.html> Acesso em: 21 maio 2018.

TEIXEIRA, Débora Pires; POMPERMAYER, Mariana Morais. Moda e sustentabilidade ambiental: marcos na obra de Ronaldo Fraga. In.: COLÓQUIO DE MODA, 9., 2013, Fortaleza. Anais... Fortaleza: REDEModa, 2013. p. 1- 10. Disponível em: <http://www.coloquiomoda.com.br/anais/Coloquio\%20de\%20Moda\%20\%202013/COMUNICACAO-ORAL/EIXO-8-SUSTENTABILIDADE_COMUNICACAO-ORAL/MODA-ESUSTENTABILIDADE-AMBIENTAL-marcos-na-obra-de-Ronaldo-Fraga.pdf>. Acesso em: 3 abr. 2017.

VIANNA, Maurício; et al. Design thinking: inovação em negócios. Rio de Janeiro: MJV Press, 2012. Disponível em: <http://www.livrodesignthinking.com.br>. Acesso em: 4 abr. 2017. 